\title{
LA CLARIDAD FILOSÓFICA Y CÓMO ALCANZARLA, SEGÚN WITTGENSTEIN
}

CARLA CORDUA

UNIVERSIDAD DE PUERTo RICO EN Río PIEDRAS

El propósito de la filosofía es la claridad, ${ }^{1}$ la comprensión clara de lo que, sin un esfuerzo especial, quedaría sumido para el filósofo en la confusión y la oscuridad. La tarea específica de la filosofía, según Wittgenstein la entiende a lo largo de toda su historia intelectual, es la elucidación o clarificación (Klärung) de los significados que forman parte de nuestras actividades y de nuestra vida. "Una obra filosófica consiste en clarificaciones" (T § 4.112). Tanto el procedimiento de la filosofía como su resultado, esto es, tanto la clarificación como la claridad, sirven para curar el pensamiento filosófico de su estado primero, el de la desorientación confusa. El filósofo trabaja principalmente sobre sí mismo (ObV 38), dice Wittgenstein, con el propósito de escapar de una condición inicial que le resulta insoportable. Por eso 'claridad filosófica' es un concepto multívoco que reúne de una manera complicada y elusiva la idea moral rectora de la existencia filosófica, su tarea y método de trabajo y los resultados que su actividad produce.

El continuo contraste entre filosofía y ciencia, que Wittgenstein desarrolla con el propósito de fijar los caracteres respectivos de las dos formas modernas de la investigación, comprende la siguiente diferencia, entre otras: el proceso de la investigación cientifica parte de la ignorancia y acaba en el descubrimiento; la filosofía, en cambio, se inicia en la ilusión, en el error y la confusión, no en la ignorancia. " "Hay que partir del error y conducir la verdad hasta donde él se encuentra. - Esto es, hay que descubrir la fuente del error pues de otro modo no nos sirve para nada escuchar la verdad. Ella no puede penetrar si otra cosa ocupa su lugar [...] Hay que encontrar el camino que lleva del error a la verdad" (Frazer 234). El error en el punto de

1 Wittgenstein se vale de una serie de expresiones alemanas emparentadas para hablar del tema de que tratamos aquí. Para lo que aquí llamamos claridad, claro, clarificar, encontramos en los originales: Übersichtlichkeit, Klarheit, Klärung, Klarlegung, Klarmachen, Klarwerden, klar, Erklärung, Erläuterung, entre otras.

2 "En filosofía nos engaña una ilusión. Pero esta ilusión es también algo y alguna vez tengo que ponérmela con total claridad frente a los ojos antes de que pueda decir que no es sino una ilusión", Manuscrito 110, 239; citado por Hilmy, 1987, p. 44. 
partida de la filosofía, como Wittgenstein la entiende, depende de que ella se ocupa de lo más familiar, el lenguaje, que dominamos sin conocerlo. Lo tenemos tan cerca que no lo vemos, ${ }^{3}$ sabemos usarlo sin vacilaciones pero, en vez de una visión sinóptica de sus operaciones y de su variedad, sólo tenemos representaciones turbias y enredadas (IF § 125). De manera que hasta lo más trivial, si lo queremos describir o examinar reflexivamente, nos suele sumir en interminables perplejidades. En conformidad con su punto de partida en lo consabido pero incomprendido, la filosofía no termina en el descubrimiento de verdades nuevas, sino en la claridad que pone fin a la confusión que padecíamos. En esta claridad que disuelve la perplejidad filosófica lucen juntamente los significados clarificados y los elementos de la confusión original. La visión global y clara de este conjunto es el único resultado de la investigación filosófica como Wittgenstein recomienda llevarla a cabo; la filosofía es una actividad que cambia al filossofo, su pensamiento y su vida, pero no cambia el lenguaje ordinario ni tampoco el mundo de las existencias espacio-temporales.

Sólo algunos de los resultados de la elucidación filosófica son expresables en palabras, otros no. Hay asuntos que no se aclaran sino cuando desaparece una perplejidad. "La solución del problema de la vida se nota en la desaparición de este problema. - ¿ ¿No es ésta la razón por la cual las personas a quienes, después de muchas dudas, se les aclara el sentido de la vida no pueden decir en qué consiste tal sentido?)" (T § 6.521). Ciertas elucidaciones se refieren a palabras y a oraciones específicas; otras conducen a replantear un problema viejo que tiende a reaparecer o enseñan a preguntar sobre un asunto de manera diferente. La filosofía consta de muchas investigaciones diversas, que coinciden, sin embargo, en el propósito de aclarar lo que pensamos y hacemos. "Investigar la naturaleza de un fenómeno es mirar más de cerca" (LFP46-47 5). "[La investigación filosófica] se puede comparar con la investigación precisa que lleva a cabo un contador autorizado de la conducción de un negocio al que dará un visto bueno sólo después de comprobar que las transacciones están claras. El propósito [de la investigación] es ofrecer una exposición sinóptica y comparativa de todas las aplicaciones, ilustraciones y concepciones del cálculo. Un panorama completo de todo lo que engendra oscuridades. $Y$ esta sinopsis debe extenderse sobre un vasto territorio, pues las raíces de nuestras ideas alcanzan lejos" (Pap § 273).

El incremento de lo que ve claramente tranquiliza al filósofo, que es alguien que quiere ver más y mejor. "La insatisfacción filosófica desaparece gracias a que vemos más" (OFM III § 85); ésta será una de las convicciones permanentes de Wittgenstein: "Lo que importa es ver" (W\&CV 146). La

3 "Quiera Dios darle al filósofo la visión [Einsicht] de lo que se encuentra ante los ojos de todos" (ObV 123). 
incomprensión y la confusión se deben a la falta de visión clara (IF § 122), la inquietud filosófica puede ser suprimida logrando una perspectiva adecuada de los asuntos atormentadores (IF § 125). Como la filosofía no es doctrinaria ni teórica en el sentido de ofrecer explicaciones hipotéticas de fenómenos, no se propone formular verdades nuevas, hacer descubrimientos o aumentar el saber. "La filosofía no hace sino poner ahí todas las cosas" (IF § 126). Es una actividad clarificadora de lo que ya hacemos y sabemos (W\&CV 78), más específicamente, de la lógica del lenguaje que es parte esencial de lo que hacemos y sabemos. Son las reglas de la sintaxis, las leyes de la formación de sistemas de oraciones, la gramática de los juegos del lenguaje, lo que principalmente tiene que llegar a ser claro mediante la investigación filosófica. Pues saber, en un sentido propio y enfático, equivale, sostiene Wittgenstein, a poder describir (IF II viii). Y una buena descripción es, precisamente, la que permite ver lo descrito con claridad; la máxima claridad la proporciona, según el filósofo, la exhibición extensa de los diversos ingredientes de una cosa y de las relaciones que mantienen entre ellos. La clarificación filosófica producirá una presentación de la manera en que las cosas que examinamos están distribuidas en un espacio (en el tiempo, por ejemplo) (IF II ix), pues nos permite abarcar las cosas y sus nexos dentro de ese campo. Nos volvemos capaces de describir de esta manera después de haber visto con claridad. De modo que la comprensión clara y satisfactoria está ligada o emparentada, para Wittgenstein, con la vista: lo que se hace manifiesto filosóficamente son relaciones conceptuales o internas y las comprendemos de veras en la medida en que somos capaces de exhibirlas en un medio espacial donde forman una configuración abarcable por la mirada (ObV 30). Los principales medios de la exposición de configuraciones formales son los números, el espacio y el tiempo. Las formas más importantes de claridad sinóptica se logran mediante la exhibición de lo que queremos ver en uno de estos medios.

Es fácil darse cuenta de que la de la comprensión clara es una noción más bien estrecha del fin de la filosofía. Excluye, desde la partida, entre sus objetos posibles, todas las cosas que se conocen hipotéticamente, como son los objetos de las ciencias. El contenido natural de los procesos temporales, la vida mental de los hombres, las situaciones mundanas, en suma, la mayor parte de los objetos del conocimiento -que se descubren de a poco, y siempre parcial y provisoriamente, desde determinado punto de vista - no pueden ser comprendidos con la claridad que Wittgenstein espera de la filosofía debido a que es imposible exhibirlos sinópticamente. Sólo los conceptos que ya sabemos usar se prestan para ser expuestos en sus posibilidades significativas o sus diversos usos establecidos. La investigación de posibilidades conceptuales, el objeto específico de la elucidación filosófica, es una actividad en extremo especializada y es esta especificidad de la filosofía, según Wittgenstein, la que determina la estrechez del ideal 
de la claridad. Para compensar, la claridad que busca Wittgenstein se deja describir con precisión y obtener fácilmente ${ }^{4}$ a pesar de la variedad de las formas del lenguaje a propósito de las cuales es preciso establecerla. Hay que agregar, además, que la noción wittgensteiniana de la comprensión clara es intensa y audazmente personal. Es el agente filosófico individual el que comprende de manera adecuada al cabo de una de sus empresas clarificatorias. ${ }^{5}$ Toda comunicación de la claridad es adventicia. Lo que induce a buscar la claridad es una perplejidad, un desasosiego, la tortura mental del que quiere salir de un laberinto que parece carecer de salida; el término del malestar coincide con la pacificación de la inteligencia de ese individuo por la claridad. Este final del proceso de investigar es tan personal como su motivación primera y como el esfuerzo por alcanzar la claridad y la paz anheladas. "La paz del pensamiento. Ésta es la meta anhelada del que filosofa" (ObV 87).

Wittgenstein desconfió siempre de que hubiera otras personas inclinadas, como él, a pensar independientemente y dudó, por eso, de que los que conocían sus trabajos pudieran comprender el sentido de lo que él tenía que decir. Aborreció la institucionalidad de la filosofía académica y, en general, se sintió ajeno a los tiempos que le habian tocado en suerte. Dice: "Nuestra civilización [...] es típicamente constructiva. Su actividad es levantar una estructura cada vez más complicada. Y también la claridad no le sirve a ella más que para este propósito y no constituye un fin en sí. -Para mí, en cambio, la claridad, la transparencia, es un fin en sí mismo. - No me interesa presentar una construcción sino tener delante de mí, transparentemente, los fundamentos de las posibles construcciones. - Mi meta es, pues, otra que la de los científicos y el curso de mis pensamientos, diferente del de ellos" (ObV 22). La civilización actual, que le sugiere la frase de la oscuridad de los tiempos presentes, no es, en principio, favorable a la filosofía que busca la claridad. Por eso a veces le parece que el filosofo cultiva, sobre todo, su propia persona: "El trabajo filosófico [... ] es mayormente un cultivo de uno mismo. Un trabajo que recae sobre la propia manera de entender [Auffassung], sobre el modo como uno ve las cosas. (Y lo que espera de ellas)" (ObV 38).

Nada parece más simple, obvio y fácil que la claridad, en particular, que la claridad de lo familiar, conocido y próximo. Sin embargo, Wittgenstein dice que la frase 'ser claro' "está ligada con todo tipo de problemas" (IF $\S 30$ ). El primero de estos problemas parece residir en que la frase 'ser

4 'La oración 'La tierra ha existido por millones de años' tiene un sentido más claro que la que dice 'La tierra ha existido en los últimos cinco minutos'. Pues, a quien sostiene lo último le preguntaría: '¿A qué observaciones se refiere esta oración y cuáles contarían contra ella?' Por el contrario, sé a qué orden de ideas pertenece la primera oración y en qué observaciones se basa" (IF II xi).

5 Cfr. Takashi Fujimoto, 1972, p. 232. 
claro' designa algo cambiante, no homogéneo, que consta de muchos casos diversos. Lo que le interesa a la filosofía, sin embargo, es la claridad conceptual y sólo ella, pero, aun en este terreno reducido a la investigación de la gramática de los conceptos, la claridad sigue siendo varia y problemática. Las matemáticas y los colores, los fenómenos psicológicos y el estudio de los ritos religiosos, los asuntos éticos y estéticos: sobre todas estas esferas de conceptos y sobre otras espera arrojar luz la filosofía de Wittgenstein. Pero hablamos tan diversamente de unas y de otras; los juegos que acompañan los distintos tipos de actividad suelen ser enteramente diferentes entre sí. Por eso es que nuestras confusiones, que queremos superar, son distintas entre sí y necesitan tratamientos curativos diferentes.

Por otra parte, 'ser claro' procede, como expresión, de la experiencia visual y conservará, usándola para referirse al pensamiento y a la comprensión de nuestras operaciones lingüísticas, su condición de imagen más o menos adecuada de la exposición o explicación de nuestros conceptos. Un filosofo que insistiera en la no espacialidad del pensamiento tendría que decir que la metáfora oculta tanto como revela. Pero éste en particular resultará ser un inconveniente menor para Wittgenstein, que exigirá, para considerar clara la explicitación de un concepto o de una relación formal, que la organización de sus diversas partes sea desplegada como un esquema o en una exposición representativa abarcable por el golpe de vista. La explicitación wittgensteiniana se afinca, pues, en el terreno de la claridad visual y saca de allí buena parte de su inspiración y de las directivas metodológicas para una filosofía no teórica de las relaciones entre conceptos.

La idea de la representación linguística o pictórica en el Tractatus es una buena ilustración de la importancia del pensamiento que aspira a visualizar en la obra de Wittgenstein. Aunque el filósofo abandona más tarde la concepción del lenguaje a que pertenece la idea de representación pictórica, ésta sirve para exhibir una tendencia del modo de pensar que se hará presente de diversas maneras en sus escritos y, en particular, a propósito del ideal de la claridad. El lenguaje completo, la oración, la proposición elemental son, dice el Tractatus, representaciones de lo que significan gracias a que se parecen o comparten algunos rasgos con aquello a que se refieren. "En la representación y lo representado tiene que haber algo idéntico para que lo uno pueda ser una pintura de lo otro" ( $\mathrm{T} \S 2.161$ ). Wittgenstein ofrece ejemplos muy variados de la relación representativa; cabe distinguirlos por el grado de la similitud visual entre los términos: retratos, dibujos, mapas, fotografías, modelos tridimensionales como maquetas, partituras musicales, etc. Lo que Wittgenstein llama en este libro "la representación lógica" (das logische Bild, T § 2.181) puede parecer que carece de la connotación visual que caracteriza casi todos los otros ejemplos de representación. Me parece que ello no es así, sin embargo, debido a que Wittgenstein extiende el vocabulario de la vista también hasta donde se trata de lo invisible. 
En efecto, la realidad y la representación lingüística comparten, según el Tractatus, nada menos que la forma lógica. "Lo que toda representación pictórica [Bild], no importa de qué clase sea, tiene que tener en común con la realidad para poder representarla correcta o incorrectamente es la forma lógica, esto es, la forma de la realidad" ( $\mathrm{T} \S 2.18$ ). Que las formas, en el sentido original de la palabra, son visuales resulta difícil de negar.

Aunque la obtención de una visión sinóptica clara, el acceso a una perspectiva desde la que se puede dominar visualmente un complejo de funciones diversas, tiene cierta preponderancia entre los resultados de la filosofía, como Wittsenstein la concibe, otros papeles de la claridad le interesan también. Desde temprano Wittgenstein destaca la clarificación lógica de los pensamientos, la claridad de las oraciones de la lógica ( $\mathrm{T} \S \S 4.112,4.116$, 6.112) como tareas de la filosofía. La palabra Erläuterung (elucidación o clarificación) aparece en el Tractatus con una doble función; ${ }^{6}$ por una parte, es el nombre técnico de las pseudoraciones filosóficass (de que consta el texto del libro de 1921) y, por la otra, designa la tarea peculiar de la filosofía y su resultado. Ella clarifica el lenguaje ordinario y el pensamiento. ${ }^{7}$ Mediante el estudio de los fenómenos lingüísticos se obtiene, dicen las Investigaciones filosóficas, "una visión clara del propósito y del funcionamiento de las palabras" (IF § 5). En estos casos, en que se trata de comprender con claridad las reglas de que depende el uso de las palabras, de poder pensarlas libres de confusión y turbiedad, la claridad filosófica tiene un carácter netamente intelectual. La investigación de la lógica del lenguaje no exige, como la clarificación de ciertos problemas éticos y estéticos, por ejemplo, la ordenación previa de los datos empíricos disponibles. Pues "el lenguaje ya está perfectamente ordenado. La dificultad reside exclusivamente en hacer que la sintaxis sea simple y sinópticamente abarcable" (W\&CV 46). Asimismo, cuando se alcanza la inteligencia de las articulaciones de una estructura complicada que la hacen capaz de desempeñar diversas funciones, la claridad es solamente una caracteristica del pensamiento que capta las leyes de las que dependen aquellas funciones ( $\mathrm{T} \S 5.45$ y 5.46 ; IF $\S \S 66,122$ ).

Pero la claridad total a la que Wittgenstein declara aspirar en último término (CorrRKM 45; IF § 133) difiere de las formas instrumentales de claridad. Pues lo que el filósofo llama "claridad perfecta" equivale a la completa eliminación (IF § 133) de lo inquietante y capaz de torturar: cuando el filósofo deja de sufrir sus perplejidades y ve que los problemas que lo atormentaban han desaparecido, cuando puede, a voluntad, dejar de hacer filosofía, la claridad lograda tiene para él, antes que nada, un carácter moral ( $\mathrm{T}$ § 6.521) que le cambia la existencia. Después de haber llegado

6 P.M.S. Hacker (1975) reclama para el parágrafo 3.263, donde Wittgenstein dice que los signos primitivos pueden ser explicados por elucidaciones que contengan tales signos, un sentido bien diferente del que 'elucidación' tiene en los parágrafos 4.112 y 6.54.

7 Véase Dan Nesher, 1978. 
a creer, en efecto, que el Tractatus resolvía los problemas de la filosofía en forma definitiva, Wittgenstein abandona, consecuentemente, la actividad filosófica. Sólo la retoma cuando ve que aquellos planteamientos eran en parte el producto de diversas confusiones y errores. Su vuelta a la filosofía está determinada por el descubrimiento de los enredos que todavía hace falta deshacer.

Además de las mencionadas, la claridad filosófica tiene ciertas funciones indirectas de gran importancia. Con exponer claramente lo que se deja decir, la filosofía consigue "significar" (bedeuten), dice Wittgenstein, lo inefable (T § 4.115). Por obra suya el límite entre lo decible y lo indecible se modifica; en vez de una frontera impasable, cuya violación se pagaría con la pérdida del sentido en la expresión y en la comunicación, la claridad filosófica crea un contraste revelador gracias al que se exhiben, por una parte, los límites del lenguaje y puede, por la otra, mostrarse desde sí (T $\S 4.121)$ lo que por quedar más allá de ellos no se deja decir. La comprensión de que el lenguaje tiene límites puede inducir a guardar el silencio en el que se muestra lo que no puede ser dicho con sentido. Tanto en el prólogo del Tractatus como en su sección final ( $T$ \& 7) se habla del callar o guardar silencio (Schweigen) en imperativo: es algo que, en ciertas condiciones, debemos hacer. Pero es manifiesto que sólo podremos cumplir con esta obligación de respetar los límites de lo decible si antes conseguimos hablar con claridad y ver, idealmente con penetración perfecta, cómo funciona el lenguaje. La orientación moral del Tractatus está estrechamente ligada con estos servicios que puede prestar la claridad filosófica y con el cambio en la existencia del filósofo que trae la pacificación del intelecto cuando puede dejar de hacer filosofía.

En las Investigaciones filosóficas, dominadas por la moral del escrutinio y la explicitación del lenguaje tal como es y no por la moral del respeto silencioso frente a la revelación de lo místico, los imperativos que encontramos tienden a ser los del investigador metódico que quiere enseñar a hacer filosofía de otra manera que la tradicional; sin embargo, todavía hay en este libro una prolongación del antiguo tema de los límites del lenguaje. "Los resultados de la filosofía son el descubrimiento de algunos casos de simple sinsentido (Unsinn) y el de los chichones que se ha conseguido el entendimiento chocando contra los límites del lenguaje. Ellos, los chichones, nos permiten conocer el verdadero valor de aquel descubrimiento" (IF § 119). ${ }^{8}$ La perspectiva lógica de la investigación enseña a respetar los límites del lenguaje, que no se dejan modificar por la actividad filosófica, que es una

8 El tema de los límites del lenguaje se debilita no sólo debido a los cambios en algunos de los intereses de Wittgenstein, sino también debido a su crítica posterior de este enfoque. En 1930 dice, según Waismann: "Anrennen gegen die Grenze der Sprache? Die Sprache ist ja kein Käfig [¿Chocar contra los límites del lenguaje? El lenguaje no es una jaula]" (ConvW 14; cfr. 12). 
entre otras actividades que sólo se pueden llevar a cabo más acá de tales límites.

La claridad filosófica representa siempre un triunfo sobre los varios obstáculos que dificultan que la lógica del lenguaje quede de manifiesto patentemente. En parte, estos obstáculos residen en el lenguaje mismo, que tiende a exhibir los asuntos de que trata y a desaparecer como exhibición que dispone de muchos recursos diversos, y, en parte, las dificultades que encuentra la clarificación filosófica dependen de nosotros. Las confusiones en que incurrimos por prejuicio, pereza, precipitación, irreflexión y motivados por inclinaciones que no controlamos, resultan difíciles de superar. Estamos acostumbrados a no ver con claridad cómo usamos el lenguaje (IF $\S \S 89,129,415)$. Peor aún, sostiene Wittgenstein, estamos dominados por un impulso natural a malentender el funcionamiento del lenguaje (CAM 43; IF $\S 109$ ). Por eso se justifica que Wittgenstein se refiera a la filosofía como "una lucha contra el embrujamiento de nuestra inteligencia por los recursos del lenguaje" (IF § 109; cfr. §§ 194, 196, 308, 339-340). Lo que vemos y comprendemos depende, además, de ciertas condiciones de la vida colectiva e individual; estas condiciones posibilitantes, consideradas desde otras formas de vida humana perfectamente concebibles o imaginables, son restricciones e impedimentos de la inteligencia, que nos ocultan lo que veríamos si nuestra perspectiva fuese diferente. Wittgenstein suele hablar de la mitología depositada en nuestro lenguaje y ligada estrechamente con nuestra visión del mundo (CAM 28, 57, 59, 60, 66, 70). Por otra parte, la falta de uniformidad del lenguaje constituye una dificultad objetiva enorme para la exposición filosófica. En vista de ello, la claridad debe ser entendida como un logro, el producto de una actividad que se puede aprender a llevar a cabo metódicamente. "Si le preocupa y perturba la naturaleza del pensamiento, de la creencia, del conocimiento y de cosas análogas, sustituya el pensamiento, etc., por la expresión verbal del pensamiento. La dificultad de esta sustitución es al mismo tiempo el propósito de hacerla. Se trata de esto: la expresión de la creencia, del pensamiento, etc., no es más que una oración. Y una oración tiene sentido sólo como miembro de un sistema lingüístico, como una expresión dentro de un cálculo" (CAM 42).

La claridad que se logra metódicamente según las instrucciones de Wittgenstein es bien específica: pone de manifiesto no cualquier cosa al azar sino los usos regulares del lenguaje. Porque la filosofía considera sólo cuestiones conceptuales, su campo de investigación es la operación usual del lenguaje, de sus partes y de las funciones de éstas. Las diversas variantes de la claridad filosófica se producen todas a propósito de investigaciones lingüísticas, también las que pueden ser llamadas morales, debido a que transforman el modo de vida del filósofo y podrían tener efectos culturales de vasto alcance. La actividad moral, como cualquier otra actividad humana, está estrechamente entremezclada con sus juegos del lenguaje. En 
ellos la estudia la filosofía y reflexionar sobre estos juegos hace patentes las condiciones lógicas de las que dependen sus posibilidades internas tanto prácticas como lingüísticas.

Las tareas explicativas de la ciencia y la filosofía son diferentes; en una ocasión Wittgenstein las comparó así: "La ciencia construye una casa con ladrillos que, una vez colocados, no se vuelven a tocar. La filosofía ordena una habitación y tiene por eso que tocar las mismas cosas muchas veces. La esencia de este procedimiento es que comienza con un enredo; no nos importa ser confusos con de que la confusión se aclare poco a poco" (LCam3032 42). Esta supuesta diferencia entre ciencia y filosofía está ligada con el distingo wittgensteiniano entre la explicación científica y la explicitación descriptiva de expresiones simbólicas. Wittgenstein usa a veces la misma palabra para nombrarlas, Explikation, pero si se considera el contexto de lo que dice, rápidamente nos convencemos de que no las confunde nunca. $\mathrm{Al}$ punto de que sostiene lo que, considerado desde fuera, se podría llamar un dualismo metodológico. "No estamos interesados en el pensamiento desde un punto de vista psicológico, en sus condiciones, causas y efectos; estamos interesados en el pensamiento en cuanto proceso simbólico." "Un símbolo es un signo junto con todas las condiciones necesarias para darle significación. 'Comprender' quiere decir captar el símbolo, no el hecho; y la comprensión es lo que brinda una explicación (no una droga o un agente externo). La explicación le agrega algo al símbolo, nos da más de dónde agarrarnos. El símbolo es autocontenido en algún sentido; se lo capta como un todo. No apunta hacia algo fuera de él, no anticipa otra cosa de una manera oscura. La comprensión de un símbolo no implica un conocimiento de si el mismo es verdadero o falso; para esto se requiere, además, el hecho" (LCam30-32 42-43). "Una explicación lógica es muy diferente de una explicación física" (LCam30-32 55).

La claridad, decíamos, resulta del escrutinio metódico del lenguaje y de la descripción de sus usos. Negativamente, se puede decir, es posible alcanzarla evitando tanto la tendencia a teorizar como la generalidad hipermétrope. "Nuestro método es puramente descriptivo; las descripciones que damos no son indicios de explicaciones" (CAM 125). Esto es: la descripción no es ni un mero paso preparatorio de la formulación de hipótesis, leyes o tesis ni un procedimiento que se limita a señalar en la dirección de lo que no se puede describir, sea porque la esencia está oculta detrás de las apariencias, sea porque sólo se la puede conocer de otra manera que describiendo. "Nosotros no debemos erigir ninguna clase de teoría. No debe haber nada hipotético en nuestras consideraciones. Toda explicación tiene que desaparecer y ser sustituida por la sola descripción" (IF § 109). Las operaciones del lenguaje, que son enormemente diversas, serán descritas en su singularidad; es preciso aprender a controlar nuestra tendencia inconsciente a ver y respetar la particularidad sino que nos impiden verla. "Si 
se considera el ejemplo del § 1 es tal vez posible vislumbrar hasta qué punto el concepto general del significado de las palabras rodea el funcionamiento del lenguaje con una bruma que hace imposible la visión clara" (IF § 5).

Sabemos que Wittgenstein subraya los varios peligros de la generalización. La generalidad más abarcante suele pertenecer al modo de representación de las cosas y su interpretación puede ocasionar muchos errores si no vemos que su universalidad incondicionada le viene de su carácter lógico-gramatical (IF § 104). Otras generalizaciones, especialmente la de los términos que designan lo que las cosas de una clase tienen en común, ejercen una gran atracción sobre nosotros, sostiene Wittgenstein, debido a nuestro menosprecio de los casos particulares. Los filósofos quieren generalizar como los científicos, están hoy día culturalmente condicionados a imitarlos, sobre todo a imitar su método (CAM 18; GF Anhang, parte II-9, 272). Pero la "sed de generalización", que tiene varias raíces, está también estrechamente ligada con la convicción de la inferioridad lógica de lo singular. "El desprecio de lo que parece menos general en lógica nace de la idea de que se trata de algo incompleto" (CAM 19). Pero, declara Wittgenstein, lo general o común no es más interesante para nosotros que las diferencias entre las cosas. "Esto caracteriza nuestra manera de pensar" (CAM 19). La mayor objeción contra la generalidad, sin embargo, es que no deja ver lo específico. Como la educación moderna nos da sin más la enfermedad de la hipermetropía - un defecto de la visión que consiste en percibir confusamente los objetos próximos debido a que su imagen se forma más allá de la retina-debemos reeducarnos en la atención de lo singular, en la capacidad de ver con claridad lo que habitualmente se nos oculta.

La crítica wittgensteiniana de la teoría y de la explicación que se practica en las ciencias contrapone la posibilidad de otros modos de explicación aclaratoria, que serían más adecuados para los efectos de entender el sentido de las cosas que la explicación hipotética. La exposición sinóptica del esquema de un proceso de desarrollo o de una colección de datos, declara Wittgenstein en sus observaciones críticas sobre el libro de Frazer, representa la manera adecuada de aclarar el sentido de lo que se trata de comprender en este y otros casos. "El concepto de la exposición sinóptica [die übersichtliche Darstellung] es de importancia fundamental para nosotros. Representa nuestra manera de exponer, la manera como vemos las cosas [...] Esta exposición sinóptica procura la comprensión, que consiste, precisamente, en que 'vemos las conexiones'" (Frazer 241). Cuando lo que se trata de aclarar son las relaciones de un conjunto complejo de cosas diferentes, la exposición adecuada de las mismas presupone un ordenamiento de la diversidad que ponga en evidencia las conexiones interesantes. "Imagina que alguien quiere darte una idea de las características faciales de cierta familia, los Menganos; lo haría mostrándote un conjunto de retratos de familia y señalando a tu atención ciertos rasgos característicos. Su principal tarea 
consistiría en hacer un arreglo adecuado de estos retratos, que te permitiría ver, por ejemplo, cómo ciertas influencias cambian gradualmente los rasgos, de qué modo característico envejecen los miembros de la familia, qué rasgos se acentúan a medida que envejecen" (CAM 125).

La prueba matemática, ${ }^{9}$ donde también se trata de comprender una operación gradual que redunda en un resultado, tiene que tener una estructura que sea captable sinópticamente. "La abarcabilidad sinóptica [Übersichtlichkeit] es parte de la prueba. Si el proceso mediante el cual obtengo el resultado fuera inabarcable, podría, sin duda, tomar nota de que este número es el producto que se obtuvo, pero, ¿qué hecho sería capaz de confirmármelo? Yo no sé lo que debería resultar" (OFM I § 154; cfr. III §§ 1-14, 22, $39,43,50$; IV § 41; VII § 20). "La prueba, podría decir, es una figura que tiene en un extremo determinadas oraciones y en el otro extremo una oración que llamamos la 'demostrada'" (OFM I \& 28). "Una nueva técnica de calcular debe proporcionarnos, precisamente, una figura nueva, un nuevo modo de expresión, y no podemos hacer nada más absurdo que tratar de describir este nuevo esquema, este nuevo tipo de estructura, mediante las viejas expresiones" (OFM II § 46). Esto no quiere decir, sin embargo, que en las pruebas muy largas y complicadas, o en las que requieren la intervención de computadoras, por ejemplo, en las que puede resultar imposible abarcar actualmente todos los pasos y relaciones que las integran, falte la requerida visión sinóptica. Pues si el método de la demostración, las reglas que gobiernan el curso de la prueba y, con ellos, la posibilidad misma de probar resultan claros y abarcables sinópticamente, tengo todo lo que hace falta, según Wittgenstein, para que haya prueba matemática. ${ }^{10}$

"No aceptamos el resultado de la prueba [matemática] porque resultó así una vez o porque resulta así a menudo. Sino porque vemos en la prueba la razón para decir que tiene que ser así" (OFM III § 39). La prueba tiene que ser un proceso que se pueda repetir con exactitud y facilidad para que reconozcamos la validez forzosa de su resultado; para cumplir con estas dos condiciones lo mejor es que ella tenga una estructura reconocible, impresionante (einprägsam) ${ }^{11}$ y memorable, que sea una configuración, dice

9 Una discusión detallada de la importancia y el sentido preciso de la consideración sinóptica para la prueba matemática se puede encontrar en S.G. Shanker, 1987, cap. 4, pp. 153, 231-234.

10 Refiriéndose polémicamente a ciertos argumentos formulados en el último tiempo contra Wittgenstein y su exigencia de Übersichtlichkeit de la prueba matemática, dice Shanker: "The point of Wittgenstein's argument, therefore, $[. .$.$] is not that we can see that 10+11$ $=21$ whereas we cannot see the same thing in stroke-notation; rather, it is that the truth of the proposition in either notation rests on the rules governing addition [...] It is the law governing the expansion of the series (in which a certain number occurs, e.g.), not the actual expansion of the series, that must be surveyable" $(1987$, p. 128).

11 "Una prueba no sólo debe mostrar que algo es así, sino que tiene que ser así. - ¿Bajo qué circunstancia muestra esto la actividad de contar? - Uno quisiera decir: cuando las cifras 
Wittgenstein, parecida a una imagen cinematográfica (OFM III § 22). El resultado demostrado es indubitable y la prueba me entera de las buenas razones para no ponerlo en duda. "Allí donde falta la visión sinóptica, esto es, donde hay lugar para la duda [... ] queda destruida la prueba" (OFM III § 43).

Toda demostración o prueba se efectúa dentro de un contexto de supuestos, hábitos, creencias, convenciones sociales, que forman un sistema. Ahora bien, si comparamos el valor relativo del proceso demostrativo con el de la nueva visión comprensiva que resulta de él, lo importante, sostiene Wittgenstein, es el ver y no la prueba. La inferencia, por ejemplo, no me da una nueva manera de ver pero razonando puedo tener la suerte de ver, de pronto, una nueva posibilidad sistemática dentro de mi manera habitual de pensar. "En el sistema en que me muevo y en el que conduzco la prueba tengo que ver el nuevo sistema. - Lo importante es el ver y no la demostración. A eso que veo, a la posibilidad del sistema, no le corresponde ninguna oración. No se asevera nada y por eso no es posible probar nada tampoco" (W\&CV 146).

Pero no sólo la claridad matemática tiene estas características. Tanto la comprensión filosófica de la esencia del lenguaje como la inteligencia empírica de un conjunto de datos cuyo sentido se trata de comprender exigen por igual que primero ordenemos la diversidad en cuestión hasta hacerla sinópticamente abarcable. "Lo que puede hacerse revisable por la vista mediante una ordenación" (IF § 92), dice Wittgenstein, nos libera de tener que buscar lo oculto, lo que supuestamente se esconde debajo de la superficie o en un interior inaccesible. Waismann ${ }^{12}$ compara el procedimiento de clarificación de Wittgenstein, al que éste llama una manera de proceder entre otras (IF § 132), el método de reunir la diversidad de lo que se trata de entender mediante la sinopsis, con la idea goetheana del esquema primordial de una planta. ${ }^{13}$ Ambos métodos logran que los datos reunidos exhiban sus relaciones internas y se mantengan juntos, coordinados en una imagen general, como dice Wittgenstein (ein allgemeines Bild). Si entre los datos de que disponemos hay lagunas of faltan algunos nexos, construiremos un caso intermedio hipotético, un órgano mediador ficticio, inventado (ein Zwischenglied, CAM 129; EPR 12). Sin embargo, no se trata de hacer una hipótesis sobre el desarrollo temporal del proceso. La exposición sinoptica no es lo mismo que la explicación histórica. "Un caso intermedio hipotético

y lo contado forman una configuración que impresiona y se graba en la memoria. Cuando tal configuración es usada de ahora en adelante en sustitución de la actividad de contar" (OFM III § 9).

12 Waismann, 1965, cap. IV, § 2.

13 Datos históricos sobre el posible origen de la idea de exposición sinóptica como proceder metódico se pueden encontrar en el primer volumen del comentario de las Investigaciones filosóficas de Baker y Hacker, 1980, pp. 531-541. 
sólo tendrá, en esta función, el papel de llamar la atención sobre el parecido entre los hechos, sobre su interconexión. Así es como ilustramos la conexión interna entre el círculo y la elipse transformando la elipse paulatinamente en un círculo: pero no para aseverar que determinada elipse se generó real e históricamente a partir de un círculo (hipótesis sobre el desarrollo) sino sólo para aguzar nuestra mirada para una relación formal" (Frazer 241-242). ${ }^{14}$

Wittgenstein ofrece algunas observaciones sobre el método de la exposición sinóptica en su conferencia sobre ética. Se trata, como siempre, de explicitar un concepto o un conjunto de relaciones formales, en este caso, el concepto de "ética". Wittgenstein parte de la definición de Moore en Principia ethica ${ }^{15}$ y describe la tarea que se ha propuesto como sigue:

Para hacerles ver lo más claramente posible lo que considero ser el tema de la ética voy a poner delante de uds. cierto número de expresiones más o menos sinónimas, cada una de las cuales puede sustituir a la definición anterior; enumerándolas deseo producir el mismo efecto que logró Galton cuando grabó muchas fotos de diferentes rostros en la misma placa fotográfica para obtener los rasgos típicos que todos tenian en común. Y tal como mostrándoles a uds. una fotografía colectiva como ésa les podría dejar ver lo típico, digamos, de un rostro chino, igualmente, si uds. recorren la fila de sinónimos que pongo ante uds., confío que podrán ver los rasgos característicos que todos tienen en común y éstos son los rasgos característicos de la ética. (ConfE 4-5)

Estas líneas fueron redactadas entre fines de 1929 y comienzos de 1930; Wittgenstein criticará nuestra inclinación a buscar lo que hay de común entre los varios usos de un concepto y problematizará el supuesto de que existe tal comunidad de rasgos fijos expresables en la definición esencial. Sustituirá, como sabemos, la noción de esencia común por la de "parecidos

14 La importancia de la analogía en el pensamiento de Wittgenstein se puede apreciar por el considerable lugar que ocupa la actividad de comparar en su método. Véase, sobre las funciones clarificatorias de la búsqueda de semejanzas y desemejanzas, F. Waismann, 1965, cap. IV, $§ 2$.

15 La definición dice: "La ética es la investigación general de lo bueno" ("Ethics is the general enquiry into what is good", ConfE 4). Wittgenstein advierte que usará el concepto en un sentido más amplio, que incluye "lo que me parece ser la parte esencial de lo que comúnmente se llama estética". La investigación, como se ve enseguida, se refiere a lo valioso en general, a lo que es verdaderamente importante, a lo que constituye el sentido de la vida, lo que hace que valga la pena vivirla, etc. (ConfE 5). La otra modificación del concepto de Moore, que Wittgenstein no menciona directamente, es la negación de que la ética pueda ser una investigación (enquiry) o pueda tener, en algún sentido, carácter teórico ( $c f r$. ConfE 6-7, $7,12)$. La definición de Moore no le sirve al conferenciante, al parecer, más que para ofrecerle al público algo que le suene familiar. 
de familia"; estos dependerían de rasgos que, gracias a sus analogias internas, redundan en una red de relaciones que sugieren parentescos entre los casos de un mismo género o especie (ConfE 9). Este cambio de enfoque no afecta, sin embargo, el método de la exposición sinóptica, para el cual una investigación conceptual será siempre varias investigaciones de los diversos usos de un concepto. La diversidad tiene que llegar a tener un patrón escrutable antes de que la podamos comprender o abarcar con la mirada. En el caso de la ética, Wittgenstein excluye primero, como Kant, los usos relativos o triviales de "bueno" y se concentra en la diversidad de lo que llama "los usos éticos o absolutos" de la palabra (ConfE 5; cfr. 6-7). Como, de acuerdo con Wittgenstein, todo discurso moral entraña ciertos abusos de lenguaje (ConfE 9-10) debido a que la moral no se ocupa de cuestiones fácticas, la investigación no puede redundar en conclusiones expresas dotadas de sentido: ellas inevitablemente violarían los límites de lo que se puede expresar con palabras. Wittgenstein se dedica, por eso, a dar ejemplos de experiencias que lo tientan a él, personalmente, a valerse de términos éticos absolutos. La conclusión de la conferencia es de carácter negativo y repite lo dicho sobre ética en el Tractatus, a saber, que los valores son radicalmente ajenos al mundo de los hechos y por eso no podemos hablar de ellos de modo normal. En este contexto la iluminación que cae sobre las cuestiones discutidas proviene exclusivamente de los ejemplos de experiencias éticas. La claridad debida a la presentación de ejemplos adecuados es, sin duda, diversa de la claridad de la prueba o la claridad de cierta ordenación de un conjunto de datos. La Übersichtlichkeit o visión sinóptica es, obviamente, el concepto de un conjunto de "parecidos de familia".

Hacer visible cierto grupo de relaciones formales por medio de la comparación con otro grupo obliga a establecer no sólo las analogías entre ellos, sino también, por cierto, las diferencias. "Lo más llamativo, fuera de los parecidos, me parecen las diferencias". "Uno querría trazar líneas que uniesen los ingredientes comunes" (Frazer 246) para que los datos entren en una configuración unitaria que sea legible, comprensible. La exposición sinóptica compara configuraciones análogas para reconocer relaciones conocidas entre ellas. Éste no es un método para descubrir algo nuevo sino sólo uno que nos faculta para incorporar a nuestra comprensión general de las cosas aquello que nos parece raro en ella, lo que nos desconcierta, nos plantea un problema o nos obsesiona. "Creo que el intento de proporcionar una explicación [científica] es erróneo porque uno no puede coordinar o reunir correctamente, sin agregar nada, más que aquello que ya sabe; y la satisfacción que se buscaba a través de la explicación se da por sí sola [con comprender lo que no entendíamos antes]" (Frazer 235).

La resolución de perplejidades estéticas plantea problemas que, aunque peculiares en varios respectos, están, en otros, muy cerca de los de la filo- 
sofía y las matemáticas. ${ }^{16}$ "En la discusión estética lo que hacemos es más bien parecido a resolver un problema de matemáticas" (LCam32-35 38). Lo que importa son las razones, no las causas; la clara exposición de las configuraciones, no las explicaciones de lo que no se puede ver. La estética es descriptiva; lo que hace, sostiene Wittgenstein, "es llamar la atención sobre ciertos rasgos, colocar las cosas lado a lado para que se exhiban estos rasgos. Decirle a una persona 'éste es el clímax' es como decirle 'ésta es la figura que resuelve el puzzle'. Nuestra atención se fija en determinado rasgo y desde ese momento en adelante vemos tal rasgo" (LCam32-35 3839). El procedimiento de ordenar las cosas lado a lado para que luzcan claramente y se las pueda describir mejor es parte del método comparativo que Wittgenstein patrocina. Los parecidos y las diferencias interesan a la comprensión clara, como vimos; los contrastes ponen de relieve los rasgos en cuestión. De los juegos del lenguaje inventados para fines metódicos de clarificación dice Wittgenstein: "Debido a que nuestro lenguaje es complejo, me valdré de estructuras más simples que pueden serle puestas lado a lado para ver cuánta luz arrojan sobre él" (LCam32-35 46-47). La exposición clara siempre implica un despliegue espacial del conjunto de elementos que se trata de ver sinópticamente y comprender con claridad: desplegarlos lado a lado para que se destaquen mutuamente y lo subentendido luzca de manera expresa. El sentido que al cabo comprendemos no es espacial, pero su exposición se vale tanto del espacio como del tiempo, si se trata de un proceso que pasa por etapas diversas, para demostrarlo visualmente.

La proximidad entre estética y filosofía es mucho mayor de lo que estamos inclinados a creer, sostiene Wittgenstein. No entienden de hechos ni los explican, sino sólo de símbolos y su clarificación (LCam30-32 43). "Fenómenos dotados de un carácter parecido al del lenguaje en la música o en la arquitectura. La irregularidad significativa en el gótico, por ejemplo" (ObV 71). "La música y, con toda seguridad, cierta música, quisiéramos llamarla un lenguaje; otra música, ciertamente no" (ObV 121). “'El sentido de una oración' es muy parecido al asunto de una 'apreciación de una obra de arte'" (EPR 29). Tal como en el caso de los problemas que nos encomienda el funcionamiento de la lengua, lo que Wittgenstein llama puzzles estéticos, por ejemplo, la razón por la cual ciertos acordes musicales nos producen determinada impresión (EPR 20) o nos sugieren ciertas representaciones, no se pueden resolver con los métodos establecidos para usos científicos. "El tipo de explicación que uno busca cuando está desconcertado y preocupado por una impresión estética no es una explicación causal, ni una que sea corroborada por la experiencia o mediante estadísticas sobre cómo es que la gente reacciona" (EPR 21; cfr. LCam32-35 38-39). "Lo que

16 "Lo que llamamos 'entender una oración' se parece en numerosos casos mucho más a la comprensión de un tema musical de lo que tendemos a creer" (CAM 167; véase todo el parágrafo 17; también ObV 71, 121, 134-136; EPR 17-18, 21-28). 
realmente necesitamos, para resolver los puzzles estéticos, son ciertas comparaciones - una agrupación que reúna determinados casos" (EPR 29). "En la medida en que se puede ver, el desasosiego al que me refiero sólo puede ser curado efectuando ciertas comparaciones peculiares, por ejemplo, llevando a cabo un arreglo con ciertas figuras musicales para comparar su efecto sobre nosotros" (EPR 20). En contraste con las elucidaciones de su método, destinadas a dejar ver más y mejor, Wittgenstein lamenta la esterilidad de los procedimientos argumentativos en filosofía. "Cuando leemos los diálogos socráticos nos viene el sentimiento: iPero qué terrible pérdida de tiempo! ¿Para qué estos argumentos que no demuestran ni aclaran nada?" (ObV 33).

La claridad se completa en el reconocimiento, aceptación o convicción de que las cosas son, en efecto, como se muestran ahí donde han sido exhibidas inequívocamente, donde, después de considerarlas, no dejan lugar a dudas. "El resultado de un cálculo no es cuestión de experiencia sino de aquello que aceptamos. $20 \times 20=400$ es una regla gramatical" (LCam30-32 92). El reconocimiento y la aceptación, como Wittgenstein los concibe, no son momentos subjetivos del proceso de comprender sino, más bien, aspectos de la conducta, partes de la acción futura (W\&CV 167) del que vio y se cercioró. Adoptamos las cosas como se nos muestran, las incorporamos en nuestra experiencia y procedemos de acuerdo con los fenómenos, que es lo único que sabemos de veras (W\&CV 45). Las diferentes formas de claridad se traducen diversamente en actos, técnicas y hábitos nuevos, todos los cuales entrañan también, como es natural, pensamientos y representaciones nuevas, cambios de opinión y de actitudes cuya razón es la visión sinóptica. Pero lo visto con claridad no acaba en los fenómenos psicológicos que forman parte de la experiencia de convencerse, sino en el reconocimiento, que se traduce, piensa Wittgenstein, en ciertos cambios de la actividad práctica de la persona persuadida.

"Una demostración es una demostración para el que la reconoce como tal. Quien no la reconoce, no la sigue como demostración, se separa de nosotros aun antes de que comencemos a hablar" (OFM I § 61). Por una parte, la aceptación de un resultado, de una explicación, satisface, pacifica (OFM I § 155); representa un punto de llegada (OFM III § 39) desde donde se pueden contemplar las cosas de acuerdo con el criterio recién comprendido y adquirido. Pero la decisión de que se ha alcanzado el punto en el que hay que reconocer y consentir, aceptar y adoptar el resultado obtenido, es una decisión personal ${ }^{17}$ del que asiste a la exhibición clara del asunto.

17 La "decisión" de aceptar o reconocer el resultado de un procedimiento es descrita por Wittgenstein a veces como algo equivalente al paso final que damos guiados por una prueba que cambia nuestras convicciones (OFM IV § 30), a veces como un proceso de precipitarse en la nueva manera de entender como consecuencia de lo visto. "Me parece que el efecto de la prueba es que la persona se precipita en la nueva regla. - Hasta ahora había calculado de 
Que la demostración sea hecha por otro o por el mismo que la admitirá, es indiferente. Lo que no puede faltar, en cambio, es el compromiso del que da el paso del reconocimiento o la aceptación, pues su asentimiento está ligado con la apropiación de la nueva idea, que será luego puesta en prácticấ por él. "Un símbolo [pertenece] a un sistema de símbolos [...] Si uso un símbolo no puedo evitar comprometerme; no es una mera correlación arbitraria de sonidos y hechos. Si digo 'esto es verde', tengo que decir que otras cosas verdes son verdes también. Me he comprometido con un futuro modo de hablar" (LCam30-32 37). Si no entiendo las costumbres de otros pueblos, dice Wittgenstein, tengo que buscar en mí algo que les corresponda y comprenderlas, así, desde lo que soy y sé. Sin "un espíritu común" (Frazer 251) no puede haber comunicación o comprensión de clase alguna. Pues tengo que tener una razón, un motivo, para aceptar que las cosas son de cierta manera. Esa razón puede estar patente en la exposición misma del asunto que considero o, en su defecto, puedo tener que buscarla en mí o en alguna circunstancia conocida por mí. "Una vez que pongo tal fenómeno en conexión con un instinto que yo mismo tengo, ésa es la explicación que buscaba, esto es, la que resuelve esta particular dificultad" (Frazer 244). Si no incorporo lo que veo claramente en mi experiencia mediante el reconocimiento de su validez o de su sentido para otros, si no acepto la legitimidad del proceso que conduce a cierto resultado, si no adopto un nuevo criterio para juzgar ciertas cosas, no puedo luego conducirme prácticamente de las maneras que pondrán de manifiesto que he entendido algo nuevo.

Como Wittgenstein reconoce que en las operaciones del consentimiento y la aceptación interviene la voluntad, la capacidad de decidirse del que se persuade, ino existe el peligro de que tal reconocimiento tome como legítimo lo que no lo es? Las razones para convencerse que forman parte de la exposición clara, ¿son una garantía suficiente contra el error? Wittgenstein no cree que se deba plantear el problema de la verdad o falsedad de nuestras técnicas y cálculos, de la legitimidad o ilegitimidad de nuestros modos habituales de actuar (LFM39 218): sólo preguntaremos cómo se hace y qué resultados produce. La ceremonia de coronación de un rey, ies acaso verdadera o falsa? A lo sumo es inútil, sostiene Wittgenstein (UFP1 § 934). Así se hace, así se suma, así conviene cultivar la tierra, así se presenta una

acuerdo con esta y esta regla; entonces alguien le presenta la prueba de que también se puede calcular de otra manera y él se pasa a otra técnica. Pero no porque piense que así también funciona, sino porque siente que la nueva técnica es idéntica a la anterior, porque tiene que darle el mismo sentido, porque las reconoce como iguales tal como reconoce este color como verde" (OFM IV § 36). En cualquier caso, es preciso llamar "decisión" al reconocimiento de la validez del resultado de una prueba o de un cálculo, pues él legitima, para nosotros, la prueba y el cálculo como tales. En este sentido el reconocimiento va más allá del resultado y es un acto libre del que comprende la relación entre las bases de la prueba, los pasos intermedios y el resultado. Véase la instructiva discusión de este punto en el ensayo de Crispin Wright, 1991, pp. 9499. 
queja ante las autoridades: son cuestiones de la práctica que también podrian hacerse de otras maneras. Estos modos de proceder consuetudinarios combinan lo necesario y lo arbitrario de maneras complicadas, pero una vez establecidos y aceptados en un grupo social son lo que son y no tiene sentido estimarlos verdaderos o falsos, fundados o infundados. Un procedimiento puede ser útil, adecuado a las circunstancias, conveniente y económico, si se lo practica no es necesario efectuar otras averiguaciones acerca del derecho que asistió a los que lo adoptaron. Los hombres en general actúan y eligen por motivos y considerando la situación en que se encuentran, pero esto no constituye una garantía de perfecta racionalidad ni justifica su manera de pensar y representarse las cosas. Los hechos no precisan de fundamentación. "No puedes decir que razonamos mal, por ejemplo, si en algún punto no aceptamos la conclusión. Podríamos decir justamente "ésta es nuestra lógica: en este caso no aceptamos la conclusión’” (LFM39 237).

$\mathrm{El}$ que comprende y se convence de algo da este paso, generalmente, por razones, aunque no es posible sostener que se trata de razones suficientes o de que las suyas son las mismas razones que convencerían a otros, a nosotros, por ejemplo. Cada uno tiene que incorporar sus nuevas persuasiones al sistema de su experiencia para hacerlas suyas. Por esto es que hay que admitir que nos persuadimos diversamente, azarosamente. Wittgenstein dice: "Vemos en la prueba la razón para decir que tiene que resultar eso. - Lo que prueba no es que esta coordinación conduzca a este resultado; sino que nos dejamos persuadir de que estos fenómenos (imágenes) deben servirnos de modelos de lo que parecerán las cosas si [...] - La prueba es nuestro nuevo modelo de cómo se presentan las cosas si no se agrega ni se quita nada, si se cuenta correctamente, etc.". "Cuando decimos durante una prueba 'esto tiene que resultar', no es por razones que no vemos. - No aceptamos el resultado porque lo hayamos obtenido, sino porque es el fin del camino. - Lo que nos convence, eso es la prueba" (OFM III § 39).

Una prueba avanza, en efecto, paso a paso mediante la analogía, con la ayuda de un paradigma. Russell da reglas de transformación y luego hace transformaciones. Parecidamente ocurre con todas las pruebas: conduces a un hombre paso a paso hasta que diga a cada paso "Sí, éste es el análogo aqui". -A la convicción matemática podría dársele la forma "Reconozco esto como análogo con aquello". Pero aquí "reconozco" está usado no como en "Reconozco que éste es Lewy" sino como en "Lo reconozco como superior a mi". Indica que acepta una convención. -Cuando digo "Sí, lo veo. Reconozco que no hay construcción del heptágono" estoy diciendo "Sí, aceptaré esto ahora; voy a hacer esto" o "Sí, veo que es la cosa más natural decir que el heptágono no se puede construir". (LFM39 62-63; cfr. 66-67)

El distingo wittgensteiniano entre causas y razones, que pertenece al contexto de su diferenciación sistemática entre la explicación científica y la 
explicitación o clarificación filosófica, incluye una referencia a la aceptación o reconocimiento de que nos estamos ocupando aquí. En efecto, la explicitación que aduce razones y no pretende explicar hipotéticamente mediante causas sólo logra lo que se propone si consigue el reconocimiento de la persona a quien se le ofrece la clarificación. "El criterio de que ésta era la [respuesta] que estaba en tu mente es que, cuando te la digo, estás de acuerdo". "La respuesta en estos casos es la que te satisfizo; por ejemplo, alguien dice (como a menudo hacemos en filosofía): 'Te diré lo que estás pensando en el fondo'"(EPR 18; cfr. 25). El que escucha una descripción de una experiencia suya tiene que poder consentir en ella para que esa descripción se refiera efectivamente a su experiencia. "Si no estuviese de acuerdo no sería ésa la explicación" (EPR 21). Hablando de la interpretación de los sueños propuesta por Freud dice: "Cuando Freud llama símbolos a ciertas imágenes, digamos la de un sombrero, o cuando dice que la imagen 'significa' esto o lo otro, está hablando de interpretar y de que se puede conseguir que el soñador acepte como una interpretación" (EPR 45).

En general, sostiene Wittgenstein, la teoría de Freud confunde la explicación científica y la clarificación conceptual; lo que ofrece es una mezcla de ambos procedimientos. Por ejemplo, el trabajo de Freud sobre el chiste y lo cómico representa bien esta confusión conceptual.

Otro asunto que Freud trata psicológicamente pero cuya investigación tiene carácter estético es el de la naturaleza de los chistes [...] Quiero examir ar en qué sentido la teoría de Freud es una hipótesis y en qué sentido no lo $\epsilon$. La parte hipotética de su teoría, el subconsciente, es la que no es satisfactoria '.... ] Cuando nos reímos sin saber por qué Freud pretende que podemos averig arlo mediante el psicoanálisis. Veo aquí una confusión entre una causa y una razón. Tener claro por qué uno se ríe no es tener claridad sobre una causa. Si lo fuera, resultaría que el acuerdo con el análisis que se ofrece del chiste como explicación de por qué te ries no sería un medio para descubrirla. Se supone que el éxito del análisis se muestra en el acuerdo de la persona. No hay nada en la física que corresponda a esto. Por cierto que podemos señalar causas de nuestra risa pero el que la persona consienta en que lo son no demuestra que ellas son de hecho'las causas. Las causas se descubren experimentalmente. La manera psicoanalítica de descubrir por qué se ríe una persona se parece a una investigación estética. Pues para que sea correcto un análisis estético tiene que haber el acuerdo de la persona a quien se le presenta el análisis. La diferencia entre una razón y una causa se pone en evidencia del modo siguiente: la investigación de una razón implica, como una parte esencial suya, nuestro acuerdo con ella, mientras que la investigación de una causa se lleva a cabo experimentalmente. [...] Por cierto, la persona que está de acuerdo con la razón no era consciente en el momento que ésa era su razón. Pero decir que la razón era subconsciente es una manera de hablar [...] El subconsciente es una entidad hipotética que obtiene su significado de las verificaciones de estas proposiciones. Lo que Freud dice del subconsciente suena a ciencia pero, de hecho, no es más que un 
medio de representación [...] No se han descubierto nuevas regiones del alma como sus escritos sugieren. La exhibición de los elementos de un sueño, por ejemplo, de un sombrero (que puede significar prácticamente cualquier cosa) es una exhibición de símiles. Tal como en la estética, las cosas se colocan unas junto a las otras para exhibir ciertos rasgos suyos. Estos rasgos arrojan luz sobre nuestra manera de considerar un sueño, son las razones del sueño. [... Es una confusión sostener que una razón es una causa vista por dentro. Una causa no se ve ni por dentro ni por fuera. Se la encuentra mediante experimentos. [A] capacitarnos para encontrar las razones de la risa, el psicoanálisis provee] nada más que una representación de procesos. (LCam32-35 39-40)

La claridad de los conceptos o de los significados y el reconocimiento y la comprensión de lo expuesto con claridad resultan de la investigación filosófica como Wittgenstein propone entenderla en las Investigaciones filosóficas y en otros escritos posteriores al año 30. "'El significado de la palabra es lo que la clarificación del significado clarifica'. Esto es, si quieres entender el uso de la palabra 'significado', entonces considera lo que se llama 'la clarificación del significado" " (IF § 560). "Ins Klare kommen" o alcanzar la claridad, dice Wittgenstein (IF $\S 314$ ), porque se trata de un logro al cabo de un proceso metódico que el filossofo describe. Pues se da también el caso de que confundimos la claridad que es obra de la descripción y la investigación con ciertas formas de pseudoclaridad. Aceptamos sin reserva, por ejemplo, ciertas apariencias de claridad, las reconocemos como cosas obvias debido a que se trata de los instrumentos y las técnicas que aplicamos habitualmente, a los que estamos acostumbrados. Todo lo familiar nos parece que lo vemos clarísimo aunque de hecho esconde muchos problemas sobre los que no hemos reflexionado. Una experiencia de claridad falsa la tenemos a propósito de ciertas imágenes del significado de las palabras que forman parte del lenguaje cotidiano y que tienden a imponérsenos como algo obvio. " 'Pero no puedes negar, por ejemplo, que al recordar ocurre un suceso interior'. - [... ] Cuando se dice: 'En efecto, al recordar sucede algo interior' se quisiera agregar ' $\mathrm{Y}$ puedes ver que es así. Es, precisamente, este suceso interno el que se designa con la palabra 'recordarse' [... ] Nos oponemos a esta imagen del 'suceso interno'. Lo que negamos es que la imagen del suceso interno nos proporcione la idea correcta del uso de la palabra 'recordar'. En efecto, lo que decimos es que esta imagen y sus ramificaciones nos impiden ver el uso de la palabra tal como es" (IF § 305; cfr. C\&E 406).

Operan en nosotros, además de las ofuscaciones de la costumbre inconsciente, ciertas tendencias naturales que, por diversos motivos, nos empujan a aceptar explicaciones o maneras de representar las cosas que parecen claras sin serlo auténticamente. Las aceptamos porque son simples, por ejemplo, o porque reducen la diversidad de lo real que nos impide orientarnos satisfactoriamente. "La atracción de ciertos tipos de explicación es abrumadora [... ] En particular, explicaciones del tipo 'En realidad, esto no 
es más que esto'" (EPR 24). Muchas teorías, la de Darwin, por ejemplo, le deben la recepción favorable que tuvieron al hecho de que explican muchas cosas a partir de un solo principio, que de pronto le parece a medio mundo "la solución obvia", dice Wittgenstein (EPR 26). Es la forma unitaria de la teoría la que persuade, no la cantidad y la solidez de la evidencia disponible en favor de su hipótesis principal. "La avidez de simplicidad. [A la gente le gustaría decir:] 'Lo único que importa son los colores'. Esto se dice sobre todo porque uno quiere que sea así. Si tu explicación es complicada resulta desagradable, especialmente si la cosa misma no te importa" (EPR 36). "Freud hizo algo diferente. No dio una explicación científica del mito antiguo. El atractivo de su sugerencia que toda ansiedad, por ejemplo, es una repetición de la ansiedad del trauma del nacimiento, no es sino el atractivo de una mitología. 'Es el resultado de algo que ocurrió hace mucho tiempo'. Casi como referirse a un tótem" (EPR 51).

La claridad filosófica obtiene una buena parte de su definición mediante el contraste que hace con estos casos de falsa claridad, como ocurre con todos los conceptos, de acuerdo con Wittgenstein. Este contraste tiene varios aspectos, el principal de los cuales es que la claridad filosófica ha sido establecida metódicamente. La pseudoclaridad de lo habitual, de lo automático o de lo que satisface una tendencia natural o un apetito, carece de aquella garantía metódica y está amenazada por la duda apenas la consideramos críticamente o en cuanto nos proponemos describirla. Por otro lado, la claridad filosófica, que no proviene de principios generales sino se debe a ejemplos cuidadosamente seleccionados, a la construcción de casos posibles que arrojan luz sobre lo que se investiga, al establecimiento de comparaciones y contrastes adecuados, es una claridad ligada al método descriptivo de la lógica del lenguaje. ${ }^{18}$

\section{BibLIOGRAFIA}

\section{Obras de Ludwig Wittgenstein}

C\&E "Ursache und Wirkung: Intuitives Erfassen", Philosophia, no. 6, pp. 391-408, 1976. ["Causa y efecto: captación intuitiva". Este trabajo se reproduce, ampliado con tres apéndices, en Wittgenstein, PO, pp. 368-426.]

CAM Preliminary Studies for the "Philosophical Investigations" generally known as the Blue and Brown Books, segunda edición, Blackwell, Oxford, 1972. [Cuadernos azul y marrón.].

ConfE "Wittgenstein's Lecture on Ethics", editado por Rush Rhees, Philosophical Review, no. 74, pp. 3-16, 1965. ["Conferencia sobre ética".]

18 Me refiero a otros aspectos de este método y sus propósitos en mi artículo "Explicación con ejemplos", Diálogos, no. 61, 1993, pp. 7-30. 
CorrRKM Letters to Russell, Keynes and Moore (1912-1948), editado con una introducción de G.H. von Wright, Cornell University Press, Ítaca, 1974. [Correspondencia con Russell, Keynes y Moore.]

EPR Lectures and Conversations on Aesthetics, Psychology and Religious Belief, compilado de las notas tomadas por Yorick Smythies, Rush Rhees y James Taylor, editado por Cyril Barrett, Blackwell, Oxford, 1970. [Lecciones y conversaciones sobre estética, psicologia y fe religiosa.]

Frazer "Bemerkungen über Frazer's The Golden Bough", Synthese, no. 17, pp. 233253, 1967. ["Observaciones sobre La rama dorada de Frazer". Este trabajo se reproduce con agregados en Wittgenstein, PO, pp. 115-155.]

GF Philosophische Grammatik, editado por Rush Rhees, en WA, vol. 4. [Gramática filosófica, trad. de Luis Felipe Segura, Instituto de Investigaciones Filosóficas, México, 1992.]

IF Philosophische Untersuchungen, editado por G.E.M. Anscombe y Rush Rhees, Suhrkamp, Francfort del Meno, 1974, en Schriften IInvestigaciones filosóficas, trad. de Alfonso García Suárez y Ulises Moulines, Instituto de Investigaciones Filosóficas/Editorial Crítica, México/Barcelona, 1988.]

LCam30-32 Wittgenstein's Lectures. Cambridge, 1930-1932, de las notas de John King y Desmond Lee, compilado por Desmond Lee, University of Chicago Press, Chicago, 1980. [Lecciones en Cambridge, 1930-1932.]

LCam32-35 Wittgenstein's Lectures. Cambridge, 1932-1935, de las notas de Alice Ambrose y Margaret MacDonald, compilado por Alice Ambrose, Rowman and Littlefield, Totowa, 1979. [Lecciones en Cambridge, 1932-1935.]

LFM39 Wittgenstein's Lectures on the Foundations of Mathematics. Cambridge, 1939, de las notas de R.G. Bosanquet, Norman Malcolm, Rush Rhees y Yorick Smythies, editado por Cora Diamond, Cornell University Press, Ítaca, 1976. [Lecciones sobre los fundamentos de las matemáticas. Cambridge, 1939.]

LFP46-47 Wittgenstein's Lectures on Philosophical Psychology, 1946-1947, notas de PT. Geach, K.J. Shah y A.C. Jackson, compilado por PT. Geach, University of Chicago Press, Chicago, 1988. [Lecciones sobre la filosofía de la psicologia, 19461947.]

ObV Vermischte Bemerkungen, una selección de sus escritos póstumos, compilado por G.H. von Wright, Suhrkamp, Francfort del Meno, 1977. [Observaciones varias.]

OFM Bemerkungen über die Grundlagen der Mathematik, compilado y adaptado por G.H. von Wright, R. Rhees y G.E.M. Anscombe, en WA, vol. 6. [Observaciones sobre los fundamentos de las matemáticas, nueva edición revisada que reproduce íntegro, aunque reordenado y con muchas adiciones, el texto de la primera edición (Blackwell, Oxford, 1964); se ha modificado bastante la división en partes y la numeración de los párrafos.]

Pap Zettel, compilado por G.E.M. Anscombe y G.H. von Wright, Blackwell, Oxford, 1967. [Papeletas.]

PO Philosophical Occasions, 1912-1951, compilado por James C. Klagge y Alfred Nordmann, Hackett, Indianápolis, 1993. [Ocasiones filosóficas.]

T Tractatus Logico-Philosophicus, Suhrkamp, Francfort del Meno, 1960, en Schriften. [Tractatus lógico-filosófico.] 
UFP1 Letzte Schriften über die Philosophie der Psychologie, Vorstudien zum zweiten Teil der philosophischen Untersuchungen, compilado por G.H. von Wright y Heikki Nyman, en WA, vol. 7. [Últimos escritos sobre la filosofía de la psicología.]

W\&CV Ludwig Wittgenstein und der Wiener Kreis, conferencias anotadas por Friedrich Waismann, escritos póstumos compilados por B.F. McGuinness, en WA, vol. 3. [Wittgenstein y el clrculo de Viena.]

WA Werkausgabe in 8 Bänden, Suhrkamp, Francfort del Meno, 1984, 8 vols.

\section{Obras de otros autores}

Ambrose, A. y M. Lazerowitz (comps.), 1972, Wittgenstein: Philosophy and Language, Allen \& Unwin, Londres.

Baker, G.P y P.M.S. Hacker, 1980, An Analytical Commentary on the Philosophical Investigations. Volume I. Wittgenstein: Understanding and Meaning, University of Chicago Press, Chicago.

Fujimoto, T., 1972, "The Notion of Erklärung", en A. Ambrose y M. Lazerowitz, 1972, pp. 222-232.

Griffiths, A.P. (comp.), 1991, Wittgenstein Centenary Essays, Cambridge University Press, Cambridge.

Hacker, P.M.S., 1975, "Frege and Wittgenstein on Elucidations", Mind, no. 84, pp. 601-609.

Hilmy, S.S., 1987, The Later Wittgenstein: The Emergence of a New Philosophical Method, Blackwell, Oxford.

Leinfellner, E. et al. (comps.), 1978, Wittgenstein und sein Einfluss auf die gegenwärtige Philosophie, Actas del segundo simposio internacional de Wittgenstein, del 29 de agosto al 4 de septiembre, 1977, Kirchberg am Wechsel (Austria), HölderPichler-Tempsky, Viena.

Nesher, D., 1978, 'The Nature and Function of 'Elucidations' in Wittgenstein's Tractatus", en E. Leinfellner et al., 1978, pp. 142-146.

Shanker, S.G., 1987, Wittgenstein and the Turning-Point in the Philosophy of Mathematics, State University of New York Press, Albany (N.Y.).

Waismann, F, ConvW, "Notes on Talks with Wittgenstein", Philosophical Review, no. 74, 1965, pp. 12-16. ["Notas sobre conversaciones con Wittgenstein".]

Wright, C., 1991, "Wittgenstein on Mathematical Proof", en A.P. Griffiths, 1991, pp. 79-99. 